\title{
Making Matters: Samples and Documentation in Digital Craftsmanship
}

\author{
Bruna Goveia da Rocha* \\ Eindhoven University of Technology \\ Eindhoven, The Netherlands \\ b.goveia.da.rocha@tue.nl
}

\author{
Janne Spork* \\ Eindhoven University of Technology \\ Eindhoven, The Netherlands \\ m.j.spork@student.tue.nl
}

\author{
Kristina Andersen \\ Eindhoven University of Technology \\ Eindhoven, The Netherlands \\ h.k.g.andersen@tue.nl
}

\section{ABSTRACT}

Digital fabrication machines enable the creation of a wide range of artifacts and materials. In the process of exploring the possibilities within these digital modes of creation, many samples are made. To encourage crosspollination between different practices and strive for a community that shares more information, this research investigates the state of the art of sample making and documentation practices in the context of Digital Craftsmanship. Through in-depth interviews with designers with a focus on digital craftsmanship, in this paper we unpack some of the practices and challenges in material driven processes related to how to design, evaluate, document and archive material samples. We reflect on making practices, what forms of knowledge are produced through making and how the use of samples in different design processes can be supported through documentation.

Permission to make digital or hard copies of all or part of this work for persona or classroom use is granted without fee provided that copies are not made or
distributed for profit or commercial advantage and that copies bear this notice and the full citation on the first page. Copyrights for components of this work owned by others than the author(s) must be honored. Abstracting with credit is permitted. To copy otherwise, or republish, to post on servers or to redistribute to lists, requires prior specific permission and/or a fee. Request permissions from Permissions@acm.org.

TEI ‘22, February 13-16, 2022, Daejeon, Republic of Korea (c) 2022 Copyright is held by the owner/author(s). Publication rights licensed to ACM.

ACM ISBN 978-1-4503-9147-4/22/02..

https://doi.org/10.1145/3490149.3502261

\section{Authors Keywords}

Digital Craftsmanship; Fabrication; Design practice.

\section{CSS Concepts}

- Human-centered computing Human computer interaction $(\mathrm{HCI})$

*Both authors contributed equally to this work

\section{INTRODUCTION}

The production of tangible things is largely driven by making. In recent years, we have seen the work of designing tangible and interactive things expand the making of satisfying and working prototypes towards the making and experimenting process inherent in the design itself. As we involve increasingly complex systems of technology for both the function and the production of our designs, the balance between human craftsmanship and digital production is renegotiated again and again. We consider this re-negotiation the core method concern of digital craftsmanship as it evolves in the meeting between design and fabrication.

Digital fabrication machines enable the creation of a wide range of artifacts and materials. This way of working has created a new perspective on making where the digital meets the hand in ever evolving ways. We

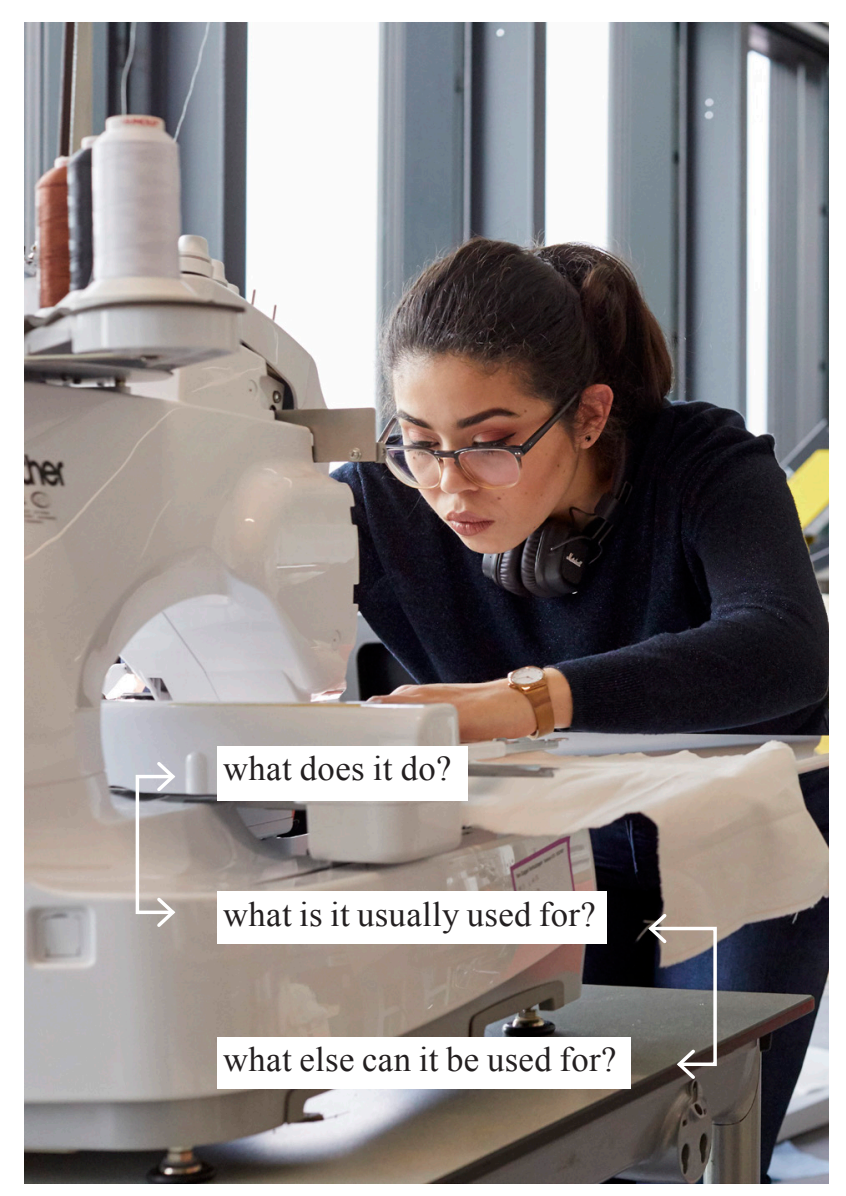


consider this a kind of digital craftsmanship, which leans equally on the capabilities of the digital machinery and the skill and craft of human hands at the intersection of the digital and non-digital [1]. In this way, digital systems are creating new possibilities for the practice of craftsmanship that then may unlock the potential of existing expressive media and encourage the creation of others [8]. Within digital craftsmanship, as in other kinds of crafts, the physical execution of an idea is not considered the final step of the process, but the starting point. In this hands-on approach of working, material exploration, physical craftsmanship and digital ways of making take center stage [2]. As designers learn by doing, they go through loops of trial and error. Here, making is a way of thinking with the hands and then letting the resulting things support imagining and talking about ideas that are difficult to fully understand or articulate solely in language [2]. Within design research, making is taking on an increasingly important role as a way of exploring. As a result, making is gaining popularity as a research method in itself [6].

\section{Samples}

In design research, the term "samples" is used to refer to the outcomes of material-driven approaches, meaning that the value and interactive possibilities offered by these prototypes are intrinsically linked to their manufacturing methods and materials [5]. The materialdriven processes result in complex encounters between intention and artifact, material and skill, chance, and opportunity [5]. This way of working is complex and multifaceted, and as a result, difficult to document and communicate [3]. The large number of samples created in material-driven processes can make documentation overwhelming, causing designers to focus instead on the communication of the end result [10].

We believe that such selective documentation of sample

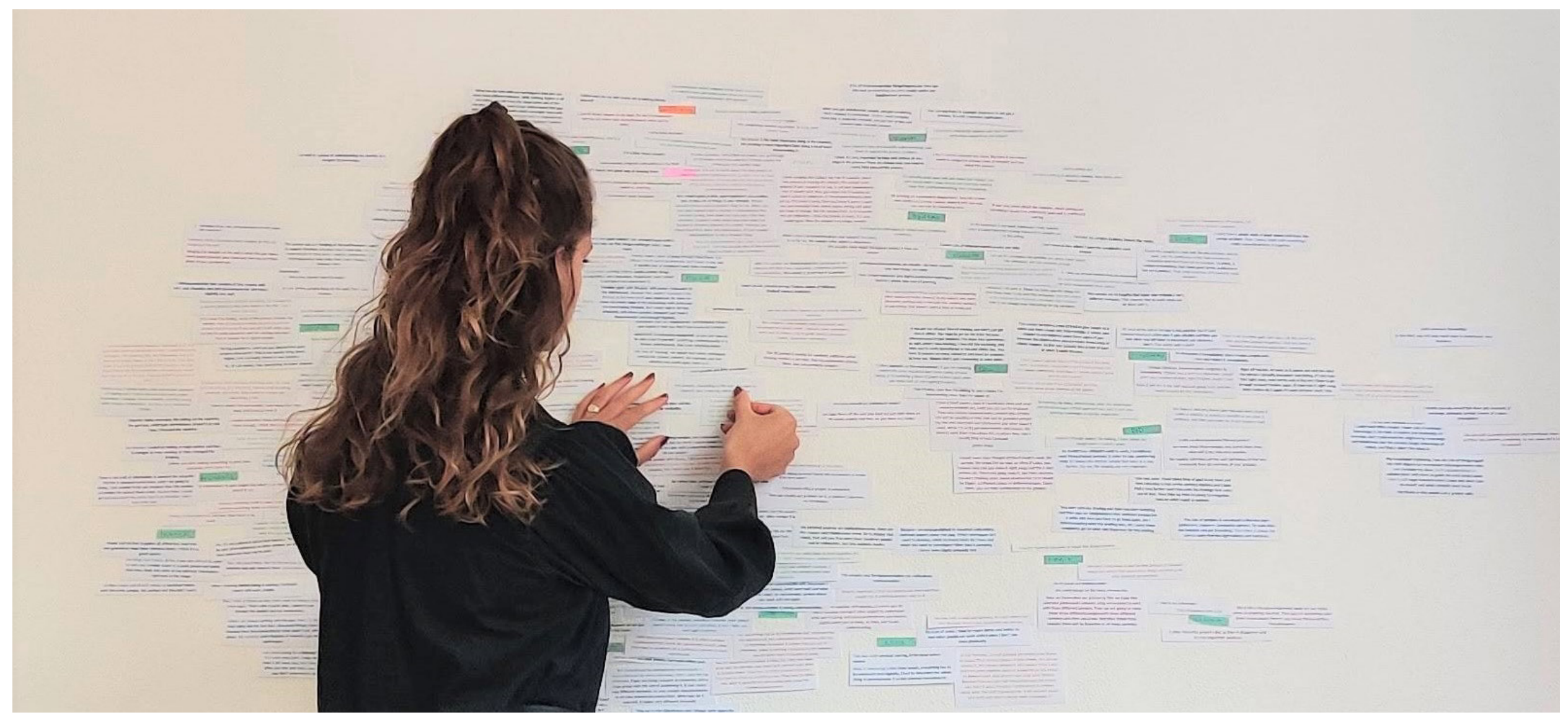


process is a missed opportunity. The high fidelity of digital fabrication makes them uniquely suited to be revisited in other design journeys [6]. However, in order for new projects to benefit from the tacit knowledge gained through previous sample making, thorough documentation is required. Such documentation may also play an important role in sharing (tacit) knowledge that can facilitate new collaborations.

To arrive at a better understanding of both common, established practices of designers and the differences that may be machine/technique dependent, we wanted to explore sample making and documentation practices in the context of digital craftsmanship. To do this, we conducted a series of in-depth interviews with design researchers and practitioners with a focus on digital craftsmanship through a wide range of techniques.

In this pictorial, we unpack their experiences and highlight some of the practices and challenges in materials-driven processes related to the tasks of making, evaluating, documenting, and archiving material samples.

In this, we do not seek to formalise ways of making or documenting, but rather to begin the work of identifying challenges and opportunities that may be encountered in how designers deal with samples within their design practices. We recognise that practices are diverse and multifaceted, and we focus on reflecting and broadening our understanding on the knowledge created in digital craftsmanship, and how digital fabrication tools support or affect these. We hope that engaging in such matters can encourage our community towards cross-pollination between techniques, practices, and ideas.

\section{INTERVIEWS}

To gain more insight in the way designers create, archive, document and use their samples, we interviewed nine design researchers and practitioners engaged with what we would consider digital craftsmanship. The selected participants had expertise in a wide range of practices based on digital fabrication machines like weaving, embroidery, 3D printing, and laser cutting.

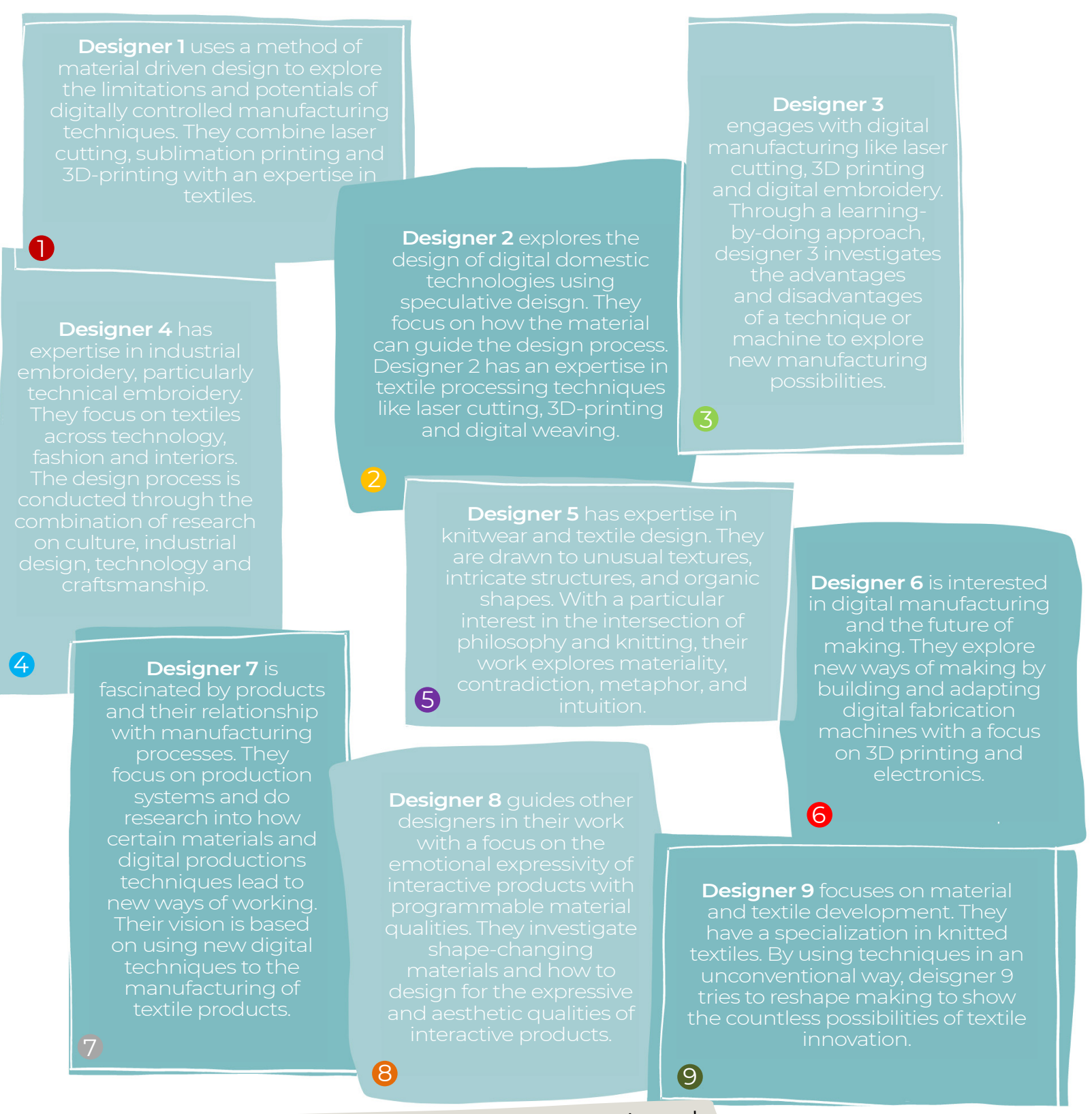

Expertise of the designers interviewed 
The in-depth interviews were conducted in two parts. The first part of the session was set up as an expert interview [11] to gain more insight about their expertise and their sample making and documentation practices. The second part was a co-reflection session [12] in which they picked a sample they had previously made as a starting point for deepening the discussion on their practices of making.

\section{Data Analysis}

During the interviews the designers highlighted the importance of having the physical and visual presence of their work around them by hanging samples on the wall. For this reason, we used the same method for the analysis. We transcribed relevant points of the interviews, printed them and clustered their experiences related to the tasks of making, evaluating, documenting, and archiving material samples.

A good deal of the information provided by the designers was in visual form. For that reason, photos provided by the designers as examples of their practices were added next to the clusters of quotes extracted from the transcribed interviews. The resulting collages or image-clouds, as we called them, attempts to preserve the richness of the designs and practices of designers engaged in the interviews. By making the clusters visual, we also leave them open for new interpretations.

\section{FINDINGS}

Our findings were clustered in four tasks: making, evaluating, documenting and archiving. We believe this division can support us in articulating challenges and knowledge gained throughout our design processes.In doing this, we aim to support furthering the efforts done by researchers in the field in finding language to discuss the outcomes and the emerging practices in digital craftsmanship [4].

Overall, it was noticeable that designers often associated the task of making samples with evaluating them. Although the documenting was sometimes part of this process of making/evaluating, the documentation itself was often grouped with the archiving of samples.
In the following sections we present our image-clouds and findings related to each of the four tasks.
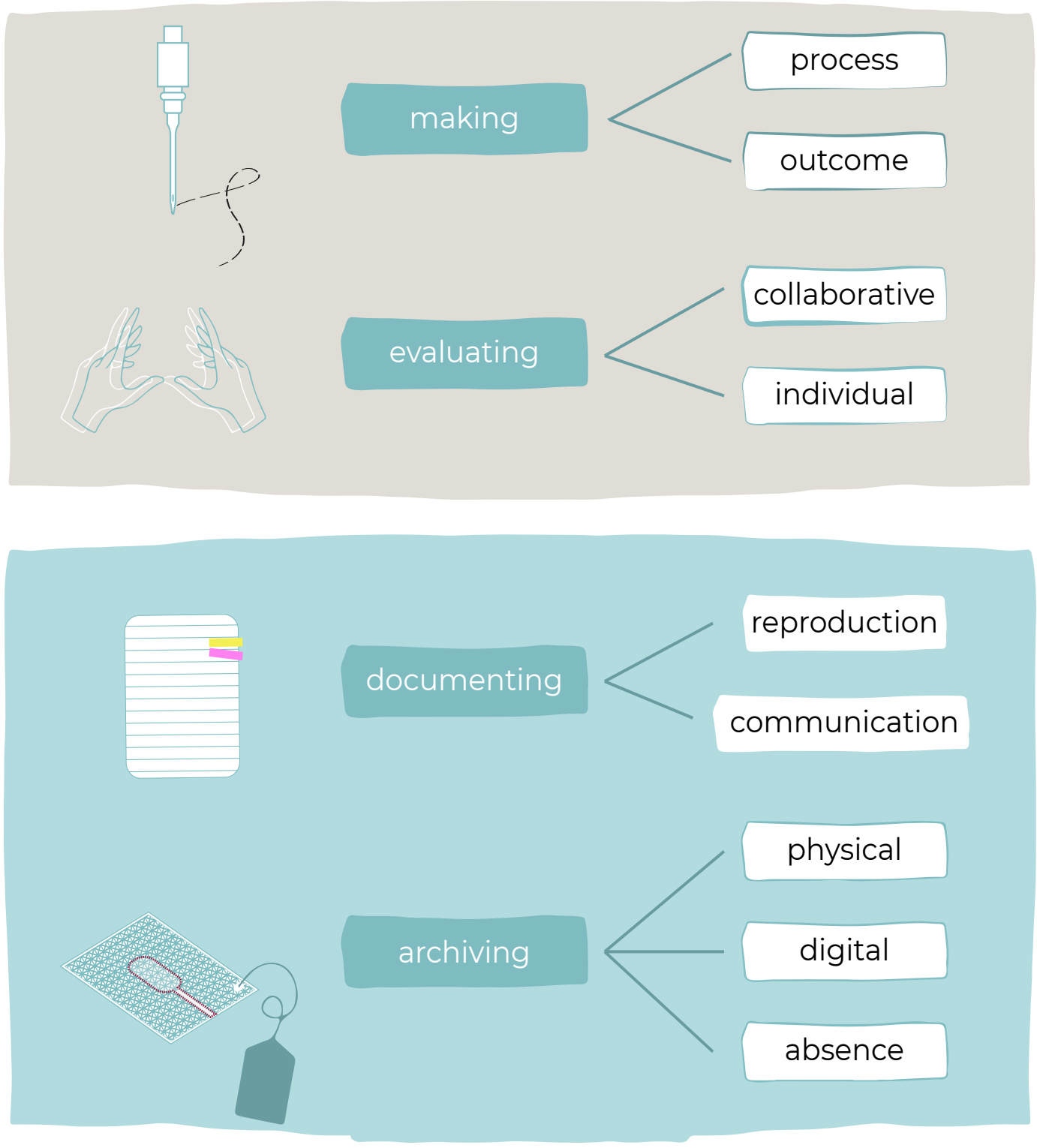


\section{Making}

The designers interviewed for this study have a wide variety of practices. From highly intuitive and exploratory methods such as material speculation, where the material drives or shapes the process, to more systematic and structured approaches. All designers are experts in digital craftsmanship: their affinity with digital production is where all their practices converge. While some focus on designing systems and delve deeper into the manufacturing process itself, for others, the creation of the physical sample is the goal.

\section{Process}

We observed that for some designers the emphasis is on the making rather than the made thing. Following the ethos of learning by doing, they determine the advantages and disadvantages of different approaches and gain knowledge through the making itself. Often the unpredictable things that occur in the development process of sample making are addressed and used as starting points for new explorations.

\section{Outcome}

For other designers interviewed, the physical sample itself plays a big role in their practice. Samples can serve as a way to take the next step. It is a way to make an idea tangible, validate it and put it into practice.

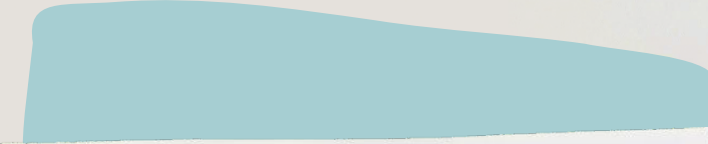

I think samples don't play a big role. It's usually about the process of making the sample. The sample itself, whether it was successful or not, is not that important to me. If it went well, then you know that it worked, so that is a kind of validation of the process that you have set up. If it doesn't work, then you know it doesn't work and you probably know where it goes wrong and what you have to change. But the sample itself, as it is usually you have to change. But the sample itself, as it is usually 6 ready again; then the sample is no longer needed no matter how efficient I want to work, I sometimes need those physical samples in order to take another big step, it's always the physical sample that takes us a step 4

\section{With only the documentation they really only know the ingredients of the recipe but not the recipe itself. Then you will be able to go in all directions.} 9

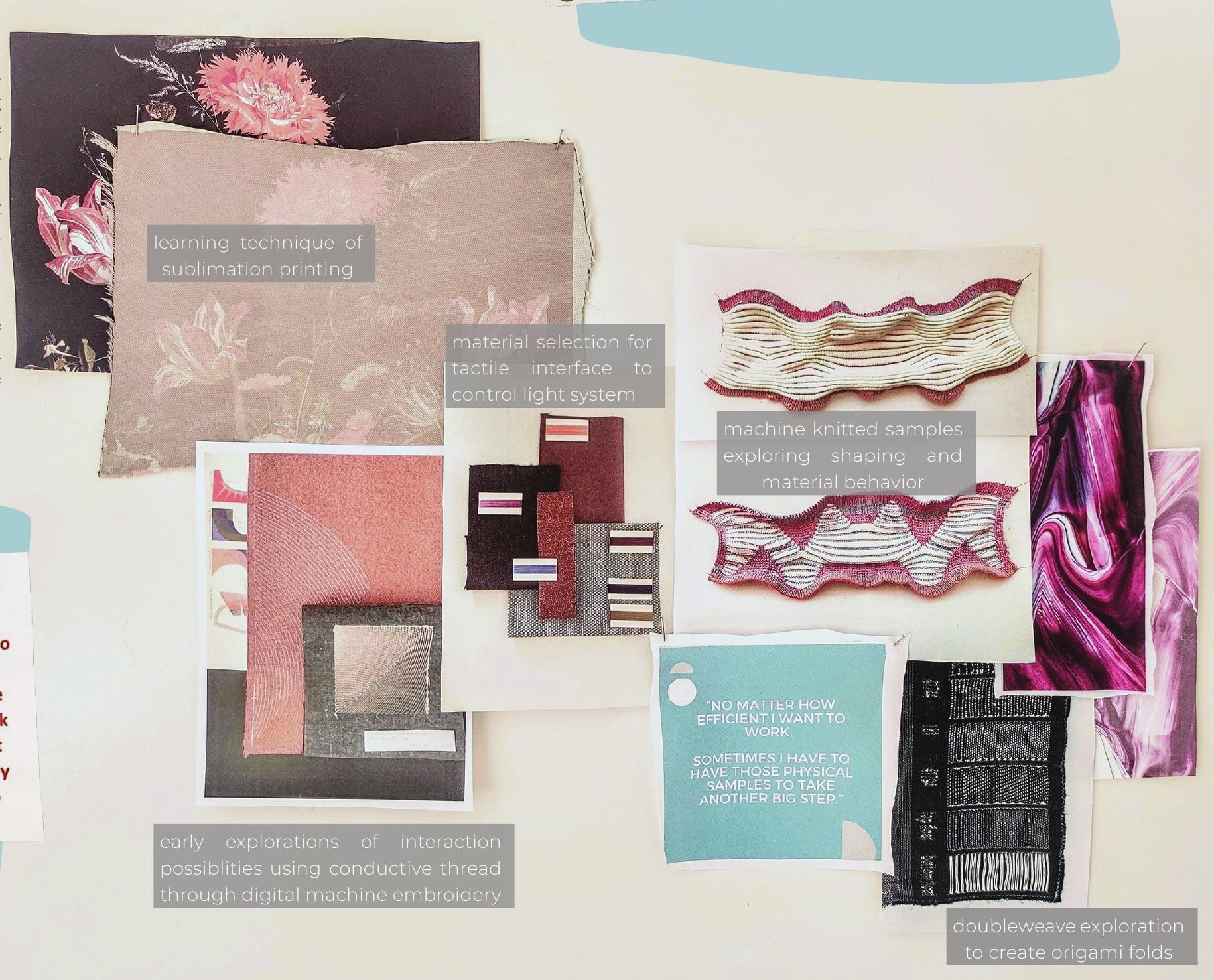




\section{Evaluating}

Depending on the type or stage of the project, samples are evaluated in different ways such as putting the samples in context, pinning them to mannequins and testing them with electronics. Some of the interviewed designers use input from others to evaluate their work. Others are more individually oriented and use their own insights as instruments of evaluation.

\section{Collaborative}

Some of the designers work collaboratively and seek outside perspectives to evaluate their process. Through showing their samples and talking about them with other people, they have a broad range of input into the process.

\section{Individual}

For others, the creative process is a very involved process with themselves. They motivate their work through their own insights.
I often work on my own so you are a walking library yourself

Everyone has their own way of writing code, the same with the setting of a $3 D$ printer, there is a lot of feeling involved. Just a little thing needs to change and

8 everything is lost.

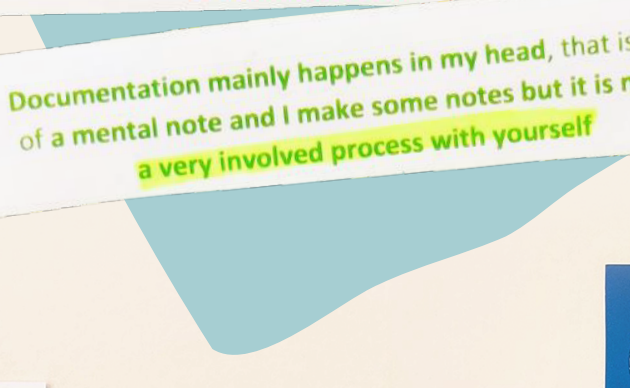

Doculy happens in my head, that is more

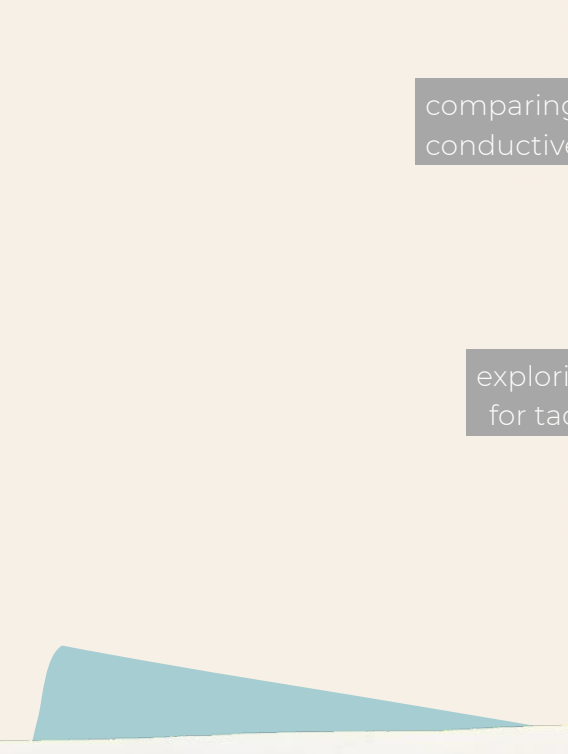

You also talk to people and then they contribute ideas and then you come to something. So you never did it all 6 by yourself.

We work in teams a lot in projects, which I really like because then you always have more people to bounce (2) ideas off of, a bit of a back-and-forth
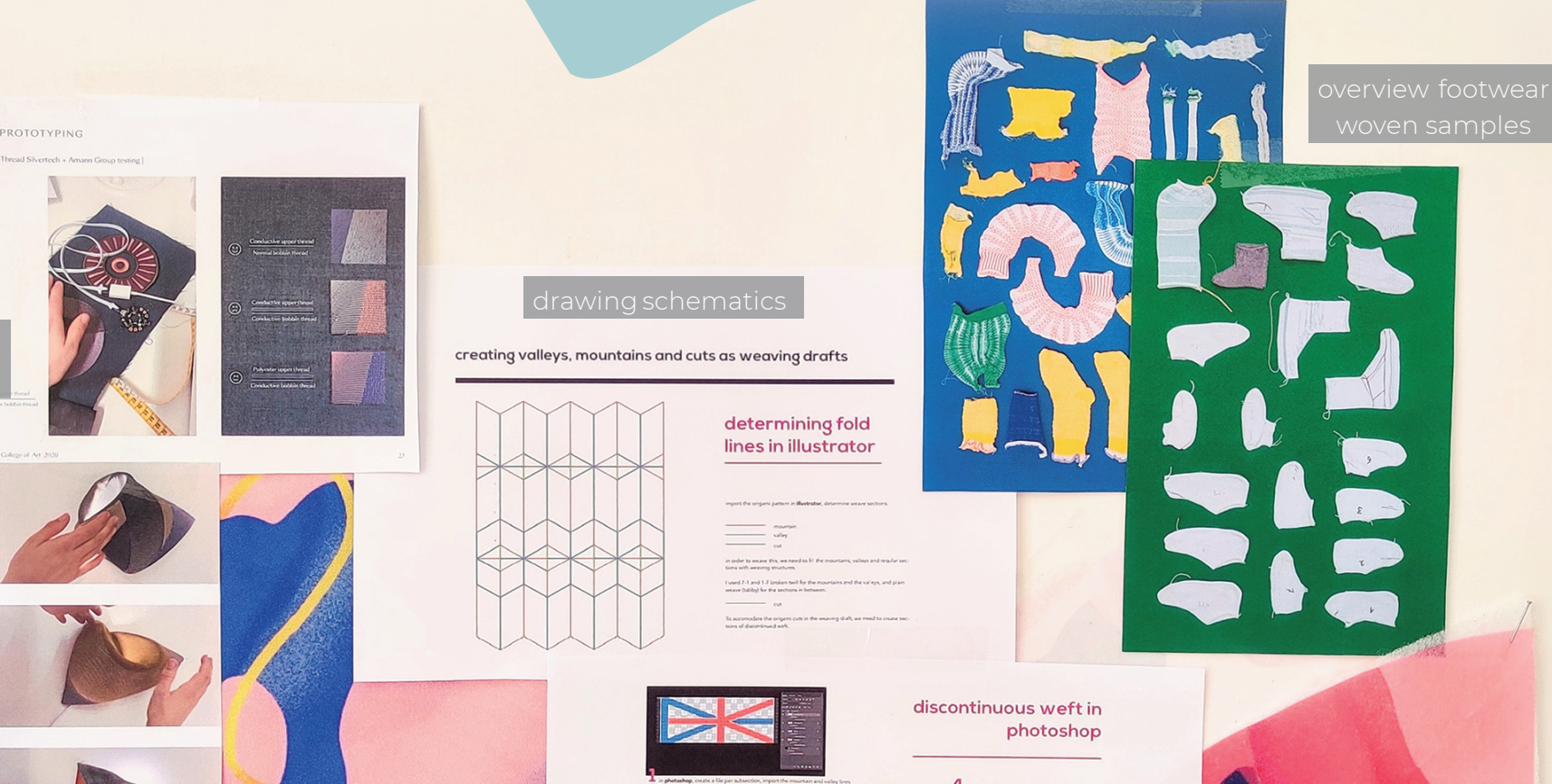

discontinuous weft in photoshop
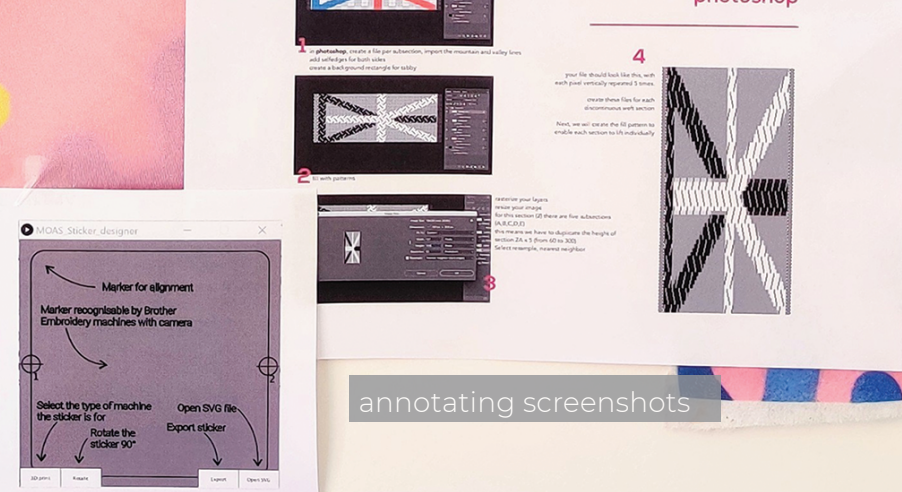

annotating screenshots 


\section{Documenting}

What the designers interviewed agreed on was that documentation should happen immediately after a sample is created. This can be contradictory. If you are in the right workflow, many iterations are made in a short period of time, making it difficult to keep up with their documentation. To keep documentation up to date, continuity is important. However, this can be easier said than done due to the different forms and formats that samples can take and because of the enthusiasm for the next steps. Next to this lack of structure, a lack of time is also a common challenge within sample documentation.

The way designers document varies from notes in text, sketches or mental notes, labels, or tags on the samples themselves (sometimes provided with a distinctive code) and photographs taken of the samples. Since all designers work with digital crafts, there are also the digital files and settings of the machinery, which are often documented within the used software.

\section{Reproduction}

Documentation can be used as a tool to enable reproduction. The importance of this varies per project and per designer. Some of the design researchers we spoke with indicated that documenting in a way that allows for future reproduction is of great importance or even value of their work. For other designers, the value of their work is not stored in the documentation. In some cases, they even have to prevent others from copying their designs.

\section{Communication}

In collaborative ways of working, documentation can play an important role. When several people are working on a project, samples and their documentation are used as a communicative tool for sharing knowledge.

If I make all the samples myself and then the other person doesn't know how to work with them, it won't help, you won't get anywhere. communication
If you get out of your flow of making, you don't just get into it either. You have to get on the train because otherwise you're just beside it. I've done that sometimes as well, when I was creating, I also did the archiving, and then you're really demolished at the end of the day. You have to process so many stimuli or you need an assistant to help you. Maybe that's just a necessity at some point.
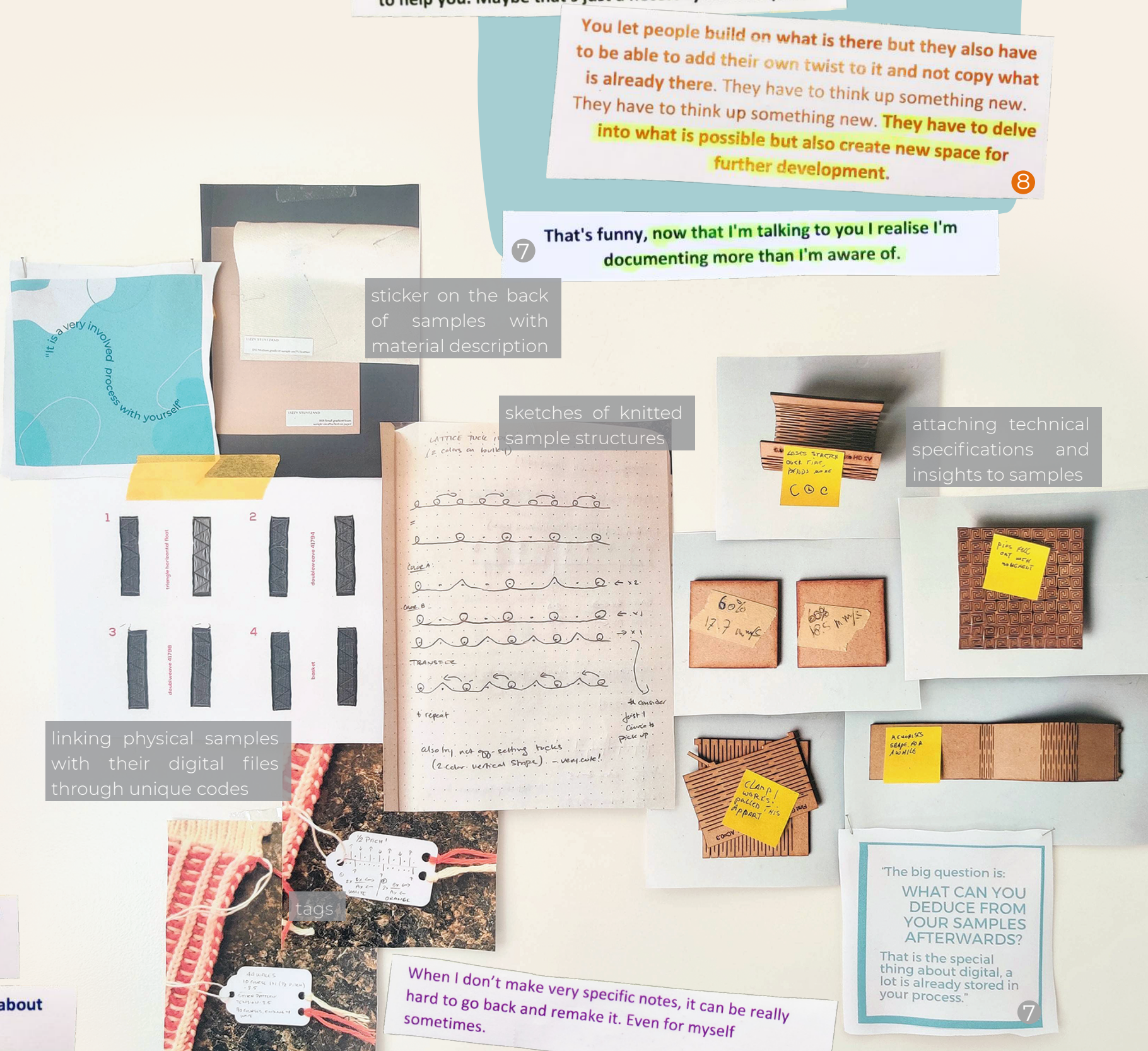

5 


\section{Archiving}

The way the samples are archived can play a role in applying the knowledge gained in future work. Among the interviewed designers, a physical and visible way of archiving is preferred, but samples often end up hidden from view or even disappear after the project is finished.

\section{Physical}

Designers stressed the importance of the physical presence of samples and the ability to feel, see and experience them. Hanging samples on the wall is one of the methods designers use to facilitate this presence and to visualize the design process. Digital imaging plays a significant role. Through photographs of samples, designers archive in a digital yet visual way. This is done for several reasons: storage along with the digital files is easy, a timestamp is automatically added to a sample, and photos are convenient to share with others.

\section{Absence}

While the designers we spoke with agreed on the importance of having samples physically present, they said that when a project is finished, samples often travel from their spot on the wall to boxes, or they disappear entirely. Some designers have a structured approach in labelling their archived samples sorted by project and date of making. For others, this structure has less value.
But a lot of iterations that don't work are not really saved or anything like that. Then you try something with them or you adapt them or you break them and then 8 they disappear.

We take an awful lot of photos and videos because you can stream super-fast and store them in a reasonably organised way. In research projects with other designers,

7 you then share a photostream.

It is much easier to retrieve much more information from a photo.
Hanging the samples on the wall is more like you have a lot of puzzle pieces in your head and then you put them down so you can zoom out.

1

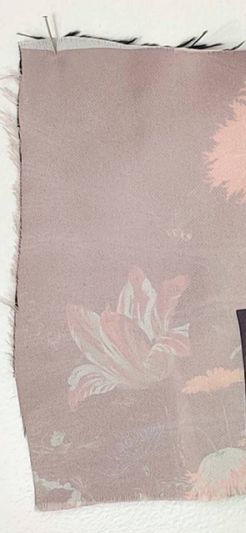

(a)

rens

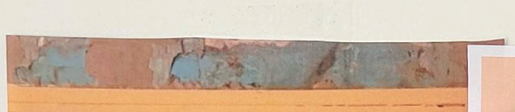

\section{.}
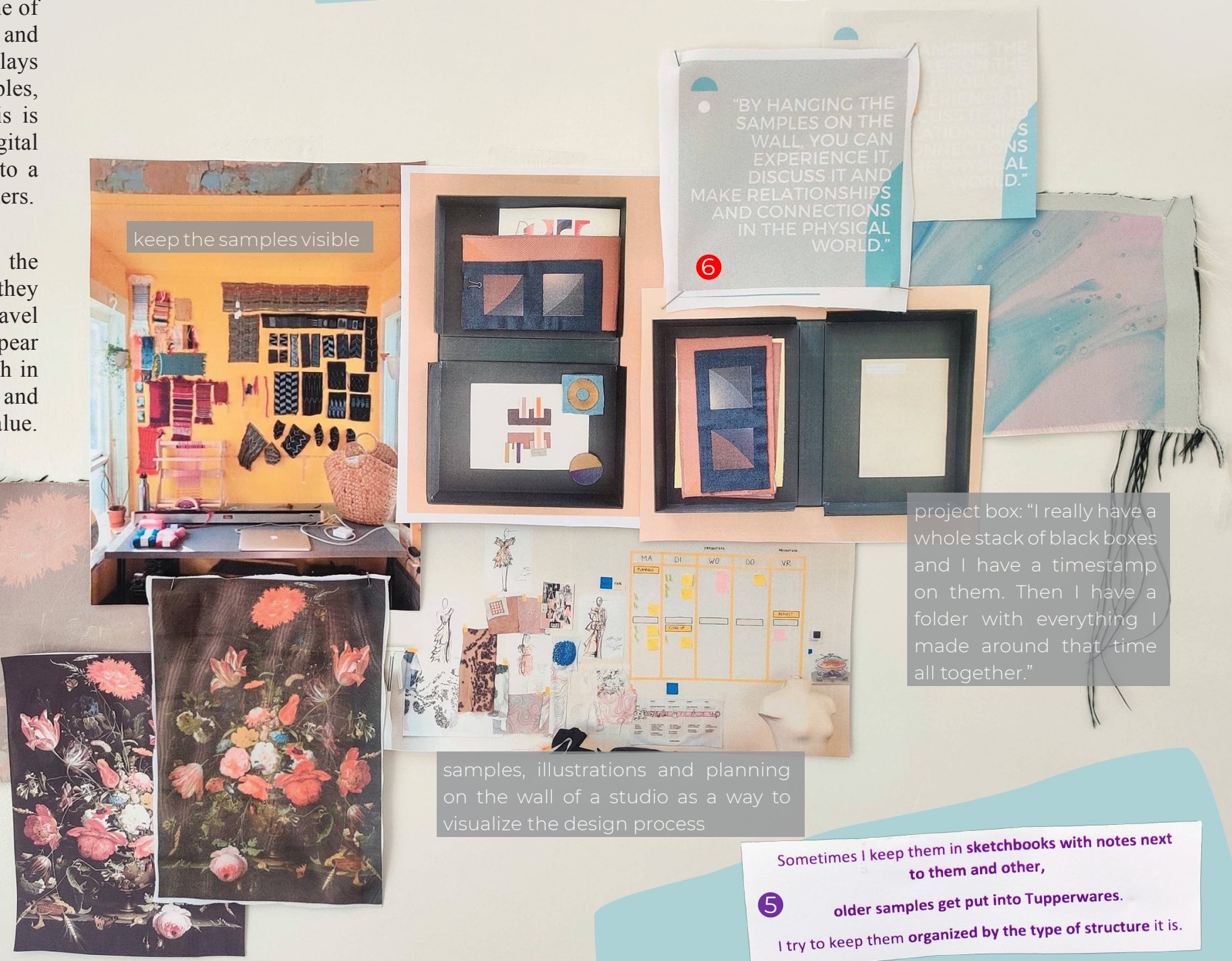

samples, illustrations and planning

on the wall of a studio as a way to

visualize the design process
(5)
Sometch in sketchbooks with notes next

$$
\text { to them and other, }
$$

older samples gen thucture it is. older samples get put into Tupperwares. 


\section{DISCUSSION}

For this process, we spoke with both design researchers and practitioners, and we found that they have distinctly different sample making practices. While practitioners are more concerned with the made thing, researchers are more concerned with the lessons they learn during the making of the artifacts or the new opportunities that a technique may open. For design researchers, it is important that they document in a way that enables other researchers to analyse the same data in order to obtain the same results as the original research study, thereby reinforcing the conclusions of the original study. For practitioners, in some cases the concern is the avoidance of reproducibility. Here it is important to mention that most designers role shift between the two identities depending on the phase of a project and their focus.

The type of crafts the designers are involved in also influences their working methods. A flat woven sample is easier to archive than a 3D-printed sample of a large volume. But whereas a 3D-printed sample can be taken straight out of the machine after creation, woven samples are often not made one by one but in batches before being taken out of the loom. This also impacts how and when designers can reflect on their proces and outcomes. With designers who work on commission, it may be that the samples they make are given away to the client, or sold separately as craft objects.

In the context of digital craftsmanship, there is an ongoing conversation about the possibilities of materials and techniques, however the ways in which these tools shape our practice are not as widely scrutinised. By exploring the current making practices, we aim to open up a conversation about practices in the context of digital fabrication and crafts.

This pictorial is an attempt at paying attention to how this process is currently managed by a series of designers active in this field. We propose that the craft technique of sample making is emerging as a key area of design work, and that paying attention to how these samples are made, interpreted, integrated and documented, provides us with suggestions as to how we may continue to incorporate new technologies and materials into our design processes.

\section{CONCLUSION}

The possibilities of exploring material properties and creating complex artifacts through digital fabrication has attracted many design researchers and practitioners into digital craftsmanship. For some of the designers we interviewed, the focus is on the making process rather than the made thing. For others, the physical sample retains the core value as an outcome. Depending on the phase and end-goal of a project, designers document more or less methodically. While some of the designers work collaboratively and seek external perspectives to evaluate their process, others motivate their work through their own insights and experiences. As a result, documentation plays different roles in different practices like supporting the reproducibility of the designs, reflecting on the knowledge gained through making or as communication tools for those working in teams. Documentation is done in text, sketches, or mental notes, labels on the samples themselves and pictures of samples. One of the main challenges reported was archiving samples. While the designers agreed on the importance of having samples physically present, they said that often when a project is finished, the samples are packed down or discarded. Other challenges include time, lack of continuity, and an over-enthusiasm for the next steps.

We are not providing guidelines or practical frameworks to how this should be addressed, nor are we proposing that there is one unique method or strategy that should be incorporated by designers in the field. This pictorial simply aims to draw attention to the processes that are already in use in digital craftsmanship, but rarely discussed or described. As designers we prefer to show that final versions and describe our process in hindsight as if there were little deviation or error. This pictorial is an attempt to pay attention to designerly strategies used inside the process, before the final design and as we are still "in the thick of it".
We believe that it is the cross-pollination between different forms of applied craftsmanship that will show us the broader range of possibilities afforded by the meeting between craft and fabrication. We hope that this short pictorial may inspire and encourage paying closer attention to the material and samples we make while working towards our design goals, in turn allowing a deeper understanding of the tools we use and the ways we might work together.

\section{ACKNOWLEDGMENTS}

We thank all the designers who generously shared their working practices with us during the interviews.

\section{REFERENCES}

[1] Kristina Andersen, Bruna Goveia da Rocha, Oscar Tomico, Marina Toeters, Angella Mackey, and Troy Nachtigall. 2019. Digital craftsmanship in the wearable senses lab. In Proceedings of the 23rd International Symposium on Wearable Computers. https://doi.org/10.1145/3341163.3346943

[2] Kristina Andersen, Ron Wakkary, Laura Devendorf, and Alex McLean. 2019. Digital craftsmachine-ship. Interactions 27,1 . https://doi. org/10.1145/3373644

[3] Peter Dalsgaard and Kim Halskov. 2012. Reflective design documentation. In Proceedings of the Designing Interactive Systems Conference on - DIS '12. https://doi. org/10.1145/2317956.2318020

[4] Raune Frankjær and Peter Dalsgaard. 2018. Understanding Craft-Based Inquiry in HCI. In Proceedings of the 2018 Designing Interactive Systems Conference (DIS '18). Association for Computing Machinery, New York, NY, USA, 473-484.tt

[5] Bruna Goveia da Rocha and Kristina Andersen. 2020. Becoming Travelers. In Companion Publication of the 2020 ACM Designing Interactive Systems Conference. https://doi. 
org/10.1145/3393914.3395881

[6] Bruna Goveia da Rocha, Oscar Tomico, Daniel Tetteroo, Kristina Andersen, and Panos Markopoulos. 2021. Embroidered Inflatables: Exploring Sample Making in Research through Design. Journal of Textile Design Research and Practice. https://doi.org/10.1080/20511787.2021.1885586

[7] Bruce Hanington and Bella Martin. 2019. Universal methods of design expanded and revised: 125 Ways to research complex problems, develop innovative ideas, and design effective solutions. Rockport publishers.
[8] Tim Ingold. 2010. The textility of making. Cambridge Journal of Economics 34, 1. https://doi. org/10.1093/cje/bep042

[9] Jennifer Jacobs, David Mellis, Amit Zoran, Cesar Torres, Joel Brandt, and Theresa Jean Tanenbaum. 2016. Digital Craftsmanship. In Proceedings of the 2016 ACM Conference Companion Publication on Designing Interactive Systems. https://doi.org/10.1145/2908805.2913018

[10] Peter Gall Krogh, Thomas Markussen, and Anne Louise Bang. 2015. Ways of DriftingFive Methods of Experimentation in Research
Through Design. https://doi.org/10.1007/978-81322-2232-3_4

[11] Michaela Pfadenhauer. 2009. At eye level: the expert interview-a talk between expert and quasiexpert (pp. 81-97). Palgrave Macmillan, London, 81-97.

[12] Oscar Tomico and Iolanda Garcia. 2011. Designers and stakeholders defining design opportunities "In Situ" through co-reflection. In Proceedings of the 3rd Conference on Participatory Innovation : 58-64. 